\title{
Review Article \\ PPAR Gamma Activity and Control of Bone Mass in Skeletal Unloading
}

\author{
P. J. Marie ${ }^{1,2}$ and K. Kaabeche ${ }^{1,2}$ \\ ${ }^{1}$ Laboratory of Osteoblast Biology and Pathology, INSERM U606, 75475 Paris Cedex 10, France \\ ${ }^{2}$ Faculty of Medicine, University of Paris 7, 75251 Paris Cedex 05, France
}

Received 2 May 2006; Revised 20 June 2006; Accepted 5 July 2006

\begin{abstract}
Bone loss occuring with unloading is associated with decreased osteoblastogenesis and increased bone marrow adipogenesis, resulting in bone loss and decreased bone formation. Here, we review the present knowledge on the role of PPAR $\gamma$ in the control of osteoblastogenesis and bone mass in skeletal unloading. We showed that PPAR $\gamma$ positively promotes adipogenesis and negatively regulates osteoblast differentiation of bone marrow stromal cells in unloading, resulting in bone loss. Manipulation of PPAR 22 expression by exogenous TGF- $\beta 2$ inhibits the exaggerated adipogenesis and corrects the balance between osteoblastogenesis and adipogenesis induced by unloading, leading to prevention of bone loss. This shows that PPAR $\gamma$ plays an important role in the control of bone mass in unloaded bone. Moreover, this opens the possibility that manipulation of PPAR $\gamma$ may correct the balance between osteoblastogenesis and adipogenesis and prevent bone loss, which may have potential implications in the treatment of bone loss in clinical conditions.
\end{abstract}

Copyright (c) 2006 P. J. Marie and K. Kaabeche. This is an open access article distributed under the Creative Commons Attribution License, which permits unrestricted use, distribution, and reproduction in any medium, provided the original work is properly cited.

\section{INTRODUCTION}

The maintainance of both bone mass and bone microarchitecture is controlled by the balance between bone resorption and formation. At the cellular level, this balance is largely dependent on the number and activity of bone forming and resorbing cells. Any alteration in the number or activity of bone cells will result in an imbalance between resorption and formation, resulting in microarchitecture deterioration and altered bone mass and strength.

The control of bone forming cells is largely influenced by weight bearing and exercise that induce mechanical forces on the skeleton. Mechanical forces induce anabolic effects by promoting bone formation at multiple levels [1-3]. Bone formation is a complex process that is dependent on the recruitment, differentiation, and function of osteoblasts. The osteogenic process starts by the commitment of osteoprogenitor cells into osteoblasts under the control of transcription factors, followed by their progressive differentiation into mature osteoblasts $[4,5]$. In the recent years, the development of cellular, molecular, and genetic studies has led to the identification of a number of important transcription factors that are essential in the control of bone formation. Specifically, several studies have provided evidence for a role of PPAR $\gamma$ in the control of bone formation and bone mass through mod- ulation of bone marrow stromal cell differentiation. In this brief review, we summarize the present knowledge on the role of PPAR $y$ in the control of osteoblastogenesis and bone mass, with a particular reference to skeletal unloading.

\section{Reciprocal relationship between osteoblastogenesis and adipogenesis in the bone marrow}

Several conditions associated with bone loss such as aging [6], glucocorticoid treatment [7], estrogen deficiency [8], or immobilization [9] are characterized by decreased osteoblastogenesis associated with increased adipogenesis in the bone marrow. This supports the concept that there is a reciprocal relationship between adipocyte and osteoblast differentiation [10]. Early studies showed that bone marrow stromal cells can be differentiated into several lineages in vitro [11-13], and that differentiation towards one lineage is dependent on local or hormonal factors [14]. Further studies showed that clonal marrow stromal cells can be differentiated into adipocytes, osteoblasts, or chondrocytes in different species including humans [15-17]. Notably, a single marrow stromal cell may have multipotential competence in vitro and differentiation towards one pathway restricts expression of other lineage-specific genes [18]. This provides evidence that adipocytes and osteoblasts are derived from a 


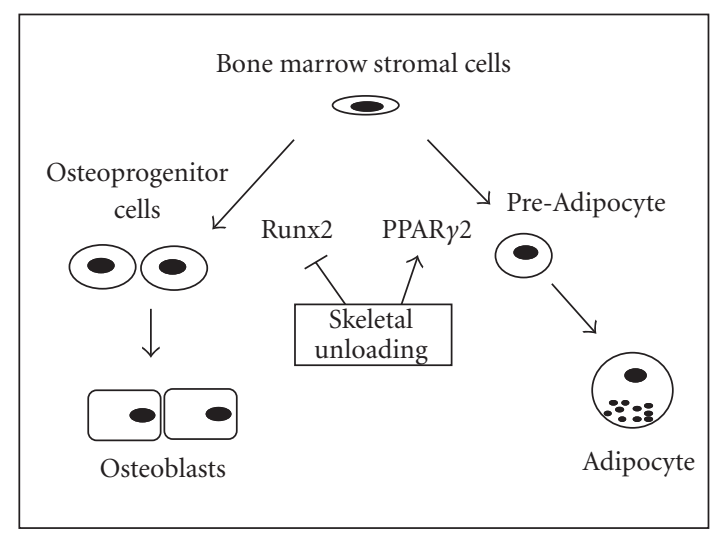

Figure 1: The in vivo differentiation of bone marrow stromal cells towards adipocytes and osteoblasts is governed by the balance between PPAR $\gamma 2$ and Runx 2 expression. In unloaded bone, decreased Runx 2 and increased PPAR $\gamma 2$ expression result in decreased osteoblastogenesis, increased adipogenesis, and bone loss.

common mesenchymal stromal cell and that a reciprocal relationship exists between osteoblastogenesis and adipogenesis in the bone marrow [10].

\section{PPAR $\gamma 2$ is a positive promoter of adipogenesis and a negative regulator of osteoblastogenesis}

The mechanisms involved in adipogenesis have been studied extensively in adipose tissue. The differentiation of preadipocytes into mature adipocytes is primarily controlled by peroxisome proliferator-activated receptor $\gamma$ (PPAR $\gamma$ ) which is a key transcription factor involved in adipocyte differentiation [19]. PPAR $\gamma$ exists in two isoforms PPAR $\gamma 1$ and $\operatorname{PPAR} \gamma 2$ as a result of alternative splicing. PPAR $\gamma 2$ is expressed at high levels in fat tissue and is essential for adipogenesis in vitro and in vivo. CCAAT/enhancer binding proteins (C/EBP) are other important transcription factors that control the expression of adipocyte genes by acting synergistically with PPAR $y$ to activate adipocyte gene expression [20]. In vitro, C/EBPs activate the expression of PPAR $\gamma$ and $\mathrm{C} / \mathrm{EBP} \alpha$ and promote PPAR $\gamma 2$ activity in preadipocyte cultures, which contributes to the expression of genes that characterize the adipocyte phenotype [21].

In bone, recent advances have been made in the role of PPAR $y$ in the interconversion of marrow stromal cells into osteoblasts or adipocytes in vitro (Figure 1). In cultured murine and human cells, PPAR $\gamma$ agonists and overexpression of PPAR $\gamma 2$ induce the differentiation of bone marrow stromal cells into the adipocyte lineage and negatively regulate osteoblast differentiation by repressing the osteoblast specific transcription factor Runx2 [22-24]. There is also evidence that PPAR $\gamma$ negatively regulates osteoblast differentiation. For example, activation of PPAR $\gamma$ with a thiazolidinediones with high affinity for PPAR $y$ increases adipogenesis and decreases osteoblastogenesis in vitro [25-27]. Additionally, activation of PPAR $\gamma$ with rosiglitazone in mice or ovariec- tomized rats decreases Runx2 expression and bone formation, and increases adipogenesis in the bone marrow, resulting in decreased bone mass $[28,29]$. Consistently, PPAR $\gamma$ haploinsufficiency in mice was shown to decrease adipogenesis and to increase Runx2 expression and bone formation, resulting in increased bone mass [30]. These findings indicate that PPAR $\gamma$ positively promotes adipogenesis and negatively regulates osteoblast differentiation of bone marrow stromal cells in vivo, suggesting that PPAR $\gamma$ is a negative regulator of bone mass.

\section{Skeletal unloading decreases osteoblast differentiation and induces bone loss}

A representative model of bone loss resulting from alterations in osteoblasts is skeletal unloading [31]. Skeletal unloading induced by hind limb suspension rapidly causes a marked trabecular bone loss in the long bone metaphysis, resulting mainly from reduced trabecular thickness and number associated with inhibition of endosteal bone formation [32]. Although both the number and activity of osteoblasts are decreased in the unloaded metaphyseal bone $[32,33]$, the number of osteoblasts is more affected than their activity [34]. Although the mechanisms underlying bone loss induced by unloading in rats are not fully understood, bone loss does not appear to result from changes in serum corticosteroid, 25-hydroxyvitamin D or PTH levels [31]. However, there is some evidence that skeletal unloading may result in part from to decreased expression [34] or response [35] to local growth factors.

The cellular mechanisms underlying the alterations of bone formation induced by skeletal unloading in rats have been partly identified [36]. We initially showed that the decreased bone formation in unloaded rat bone results from an impaired recruitment of osteoblast precursor cells in the bone marrow stroma and in the metaphysis [33]. In addition to affect osteoblast recruitment, skeletal unloading in this model alters the function of differentiated osteoblasts. This is reflected by the decreased expression of bone matrix type- 1 collagen and osteocalcin and osteopontin mRNA levels [3740 ], which correlates well with the decreased bone matrix synthesis measured at the tissue level $[32,33]$. These findings indicate that removal of mechanical forces on the skeleton rapidly alters both the recruitment of osteoblast progenitor cell and the function of differentiated osteoblasts, resulting in a marked reduction of bone formation. Such alterations are consistent with the effects of unloading in other rat models in which there is a reduction of the osteogenic capacity of bone marrow osteoblast precursor cells and a decreased expression of bone matrix proteins in rat long bones [41, 42].

\section{PPAR $y$ controls the osteoblast/adipocyte relationship in unloaded bone}

The altered bone metabolism induced by skeletal unloading is asociated with alterations in transcription factor expression. Specifically, the decreased osteoblastogenesis and bone formation induced by skeletal unloading in rats are 


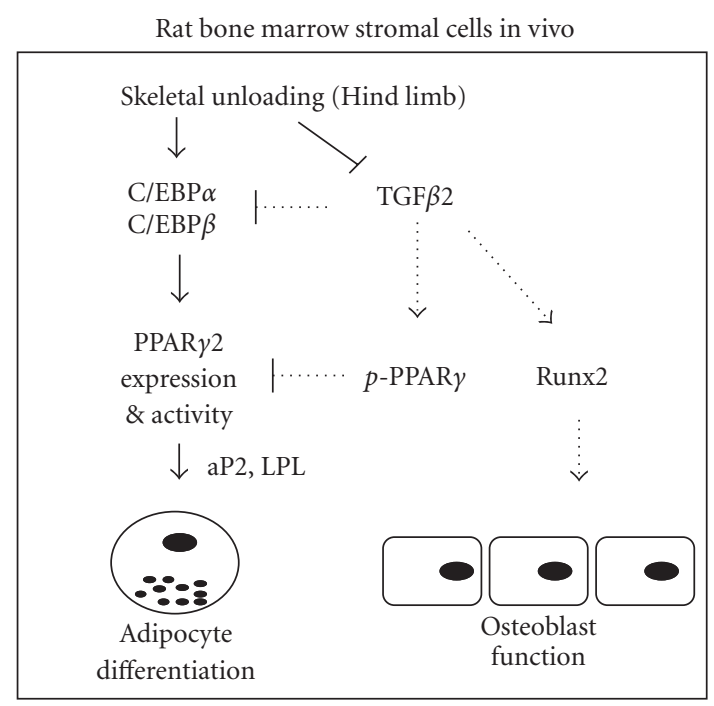

Figure 2: Skeletal unloading decreases TGF- $\beta$ expression and activates the expression of $\mathrm{C} / \mathrm{EBP} \alpha, \mathrm{C} / \mathrm{EBP} \beta$, and $\operatorname{PPAR} \gamma 2$, resulting in activation of adipocyte gene expression such as adipocytic differentiation-related genes adipocyte binding protein (aP2) and lipoprotein lipase (LPL) in bone marrow stromal cells. Exogenous TGF- $\beta 2$ (dotted lines) reduces $\mathrm{C} / \mathrm{EBP} \alpha, \mathrm{C} / \mathrm{EBP} \beta$, and PPAR $\gamma$ expressions, induces PPAR $\gamma$ phosphorylation ( $p$-PPAR $\gamma)$, and increases Runx2 expression, resulting in decreased adipogenesis, increased osteoblast function, and prevention of bone loss.

associated with reduced Runx2 expression [34]. Additionally, we showed that skeletal unloading is associated with increased adipocyte differentiation in the bone marrow stroma [43], suggesting that unloading not only impairs osteoprogenitor cell differentiation into osteoblasts but also promotes adipocyte differentiation. The exagerated reciprocal relationship between osteoblastogenesis and adipogenesis may account for the decreased bone formation associated with the increased bone marrow adipogenesis in unloaded rats (Figure 1).

Interestingly, the adipogenic differentiation of bone marrow stromal cells in unloaded bone is consistent with the temporal gene expression observed during adipocyte differentiation in vitro. Specifically, skeletal unloading in rats increases $\mathrm{C} / \mathrm{EBP} \alpha$ and $\mathrm{C} / \mathrm{EBP} \beta$ expression followed by increased expression of PPAR $\gamma$, resulting in activation of adipocyte gene expression such as adipocytic differentiationrelated genes adipocyte binding protein (aP2) and lipoprotein lipase (LPL) in bone marrow stromal cells [44] (Figure 2). Thus, PPAR $y$ with other transcription factors are involved in adipogenic conversion of bone marrow stromal cells in vivo, indicating that PPAR $\gamma$ is a negative regulator of bone mass in unloaded rats.

The mechanisms underlying the expression of Runx2 and PPAR $y$ in unloaded bone may involve decreased signaling pathways that are normally transmitted by loading. Mechanical forces are believed to transduce signals through cell-matrix interactions [45-48]. Part of the communication between the matrix and cells is ensured by integrins which interact with bone matrix proteins [49]. In bone, integrinmatrix interactions are important modulators of osteoblast differentiation in vitro $[50,51]$. It is thus possible that the lack of mechanical strain is induced by unloading results in decreased integrin-matrix interactions and signaling, and consequently decreased osteoblast differentiation. This is supported by the finding that mechanical forces increase Runx2 expression in cultured preosteoblastic cells [52]. One recent study indicates that stretching induces downregulation of PPAR $\gamma 2$ and adipocyte differentiation in mouse preadipocytes [53], suggesting that mechanical forces may play a dual role in the control of Runx 2 and PPAR $y$ expression in preosteoblasts.

How mechanical signals may modulate PPAR $\gamma$ expression or activity and thereby induce adipogenesis rather than osteoblastogenesis in bone marrow stromal cells is not fully understood. One interesting hypothesis is that specific pathways controlling osteoblastogenesis/adipogenesis may be sensitive to biomechanical forces. For example, changes in cell shape or modulation of the cytoskeletal-related GTPase RhoA were recently found to induce stem cell adipogenic or osteoblast differentiation [54]. Additionally, multiple signal pathways, including ERK and Wnt signaling, may control the balance between adipogenesis and osteoblastogenesis in vitro $[53,55]$. It remains however to determine which pathway may be involved in the altered balance between osteoblastogenesis and adipogenesis in vivo.

\section{TGF beta is a negative regulator of PPAR $\gamma$ and adipogenesis in unloaded rats}

Transforming growth factor beta (TGF- $\beta$ ) is an important regulator of bone formation by modulating osteoblastic cell proliferation and differentiation [56]. Additionally, TGF- $\beta$ is also an important modulator of adipocyte differentiation. TGF- $\beta$ inhibits adipogenesis in preadipocyte cell lines and reduces adipocyte differentiation in vitro $[57,58]$. In vivo, we found that skeletal unloading results in a rapid reduction in TGF- $\beta 1$ and TGF- $\beta$ receptor II mRNA expression in bone marrow stromal cells [34]. Others found reduced TGF- $\beta 2$ mRNA levels in bone marrow stromal cells in this model [37], suggesting that TGF- $\beta$ signaling may mediate part of the altered bone formation induced by unloading. Although diminished, TGF- $\beta$ receptors can still be activated by TGF- $\beta$ since we showed that exogenous TGF- $\beta 2$ in unloaded rats increased Runx2 expression and osteoblastogenesis, resulting in prevention of trabecular bone loss [59]. Beside this positive effect on osteoblastogenesis, TGF- $\beta 2$ administration downregulated the expression of $\mathrm{C} / \mathrm{EBP} \alpha, \mathrm{C} / \mathrm{EBP} \beta$, and PPAR $\gamma$ in bone marrow stromal cells, and reduced the expression of adipocyte genes such as aP2 and LPL in bone marrow stromal cells, thus preventing the adipocyte conversion of bone marrow stromal cells induced by unloading $[43,44]$. This indicates that TGF- $\beta$ is a negative regulator of PPAR $y$ and adipogenesis in unloaded rats (Figure 2).

One mechanism by which TGF- $\beta$ may negatively regulate adipogenesis in unloaded rats is through MAPK activation. 
TGF- $\beta$ is known to induce phosphorylation of PPAR $\gamma$ in adipocyte cells, and MAPK-dependent PPAR $\gamma$ phosphorylation results in the reduction of PPAR $\gamma$ transcriptional activity and repression of adipocyte differentiation [60-62]. In vitro, ERK activation was found to induce osteogenic differentiation of human mesenchymal stem cells, whereas its inhibition induces adipogenic differentiation [63]. In unloaded bone, we showed that TGF- $\beta 2$ increased PPAR $\gamma$ phosphorylation and inhibited adipocyte differentiation of bone marrow stromal cells through MAPK phosphorylation [44]. Thus, exogenous TGF- $\beta$ can inhibit the excessive adipogenic differentiation induced by skeletal unloading by reducing PPAR $\gamma 2$ expression, resulting in the inhibition of adipogenesis. This effect, combined with the upregulation of Runx2 expression and osteoblast differentiation induced by exogenous TGF- $\beta$ on bone marrow stromal cells, leads to correcting the imbalance between osteoblastogenesis and adipogenesis and results in a positive effect on bone mass (Figure 2). This demonstrates that appropriate manipulation of PPAR $\gamma 2$ expression in vivo can lead to prevent bone loss in unloaded bone.

\section{CONCLUSION}

There is now clear evidence that PPAR $\gamma$ plays an important role in the control of marrow stromal cell differentiation to osteoblasts or adipocytes in unloaded bone. In this model, PPAR $\gamma$ positively promotes adipogenesis and negatively regulates osteoblast differentiation of bone marrow stromal cells, indicating that PPAR $\gamma$ is a negative regulator of bone mass. This concept provides a possible target for therapeutic intervention in osteopenic disorders characterized by altered osteoblast and adipocyte differentiation of bone marrow stromal cells [64]. As an example, we showed that exogenous manipulation of PPAR $\gamma$ expression by TGF- $\beta$ can inhibit adipogenesis induced by skeletal unloading and correct the balance between osteoblastogenesis and adipogenesis, resulting in prevention of bone loss. This opens the possibility that manipulation of PPAR $\gamma$ may have potential implications in the treatment of bone loss associated with immobilization [65].

\section{ACKNOWLEDGMENTS}

The authors thank the contributors in P. Marie's group at Inserm U606 and the collaborators at IMASSA-CERMA (Département de Physiologie Aérospatiale, Brétigny sur Orge, France) for their contribution. The work presented was supported in part by grants from the Centre National d'Etudes Spatiales (CNES, Paris, France).

\section{REFERENCES}

[1] Marie PJ. The effects of microgravity on skeletal remodeling and bone cells. In: Massaro EJ, Rogers JM, eds. The Skeleton: Biochemical Genetic, and Molecular Interactions in Development an Homeostasis. Vol 18. New Jersey: Humana Press; 2004:263-276.
[2] Marie PJ, Jones D, Vico L, Zallone A, Hinsenkamp M, Cancedda R. Osteobiology, strain, and microgravity. Part I: studies at the cellular level. Calcified Tissue International. 2000;67(1):2-9.

[3] Vico L, Hinsenkamp M, Jones D, Marie PJ, Zallone A, Cancedda R. Osteobiology, Strain, and Microgravity. Part II: studies at the Tissue Level. Calcified Tissue International. 2001;68(1):1-10.

[4] Aubin JE. Regulation of osteoblast formation and function. Reviews in Endocrine and Metabolic Disorders. 2001;2(1):8194.

[5] Wagner EF, Karsenty G. Genetic control of skeletal development. Current Opinion in Genetics and Development. 2001;11(5):527-532.

[6] Meunier P, Aaron J, Edouard C, Vignon G. Osteoporosis and the replacement of cell populations of the marrow by adipose tissue. A quantitative study of 84 iliac bone biopsies. Clinical Orthopaedics and Related Research. 1971;80:147-154.

[7] Wang GJ, Sweet DE, Reger SI. Fat-cell changes as a mechanism of avascular necrosis of the femoral head in cortisonetreated rabbits. Journal of Bone and Joint Surgery - Series A. 1977;59(6):729-735.

[8] Martin RB, Zissimos SL. Relationships between marrow fat and bone turnover in ovariectomized and intact rats. Bone. 1991;12(2):123-131.

[9] Minaire P, Edouard C, Arlot M, Meunier PJ. Marrow changes in paraplegic patients. Calcified Tissue International. 1984;36(3):338-340.

[10] Nuttall ME, Gimble JM. Controlling the balance between osteoblastogenesis and adipogenesis and the consequent therapeutic implications. Current Opinion in Pharmacology. 2004;4(3):290-294.

[11] Friedenstein AJ. Osteogenic stem cells in the bone marrow. Journal of Bone and Mineral Research. 1990;7:243-272.

[12] Bennett JH, Joyner CJ, Triffitt JT, Owen ME. Adipocytic cells cultured from marrow have osteogenic potential. Journal of Cell Science. 1991;99(pt 1):131-139.

[13] Beresford JN, Bennett JH, Devlin C, Leboy PS, Owen ME. Evidence for an inverse relationship between the differentiation of adipocytic and osteogenic cells in rat marrow stromal cell cultures. Journal of Cell Science. 1992;102(pt 2):341-351.

[14] Gimble JM, Robinson CE, Wu X, Kelly KA. The function of adipocytes in the bone marrow stroma: an update. Bone. 1996;19(5):421-428.

[15] Pittenger MF, Mackay AM, Beck SC, et al. Multilineage potential of adult human mesenchymal stem cells. Science. 1999;284(5411):143-147.

[16] Oyajobi BO, Lomri A, Hott M, Marie PJ. Isolation and characterization of human clonogenic osteoblast progenitors immunoselected from fetal bone marrow stroma using STRO-1 monoclonal antibody. Journal of Bone and Mineral Research. 1999;14(3):351-361.

[17] Dennis JE, Merriam A, Awadallah A, Yoo JU, Johnstone B, Caplan AI. A quadripotential mesenchymal progenitor cell isolated from the marrow of an adult mouse. Journal of Bone and Mineral Research. 1999;14(5):700-709.

[18] Ahdjoudj S, Lasmoles F, Oyajobi BO, Lomri A, Delannoy Ph, Marie PJ. Reciprocal control of osteoblast/chondroblast and osteoblast/adipocyte differentiation of multipotential clonal human marrow stromal F/STRO- $1^{+}$cells. Journal of Cellular Biochemistry. 2001;81(1):23-38.

[19] Tontonoz P, Hu E, Spiegelman BM. Regulation of adipocyte gene expression and differentiation by peroxisome proliferator 
activated receptor $\gamma$. Current Opinion in Genetics and Development. 1995;5(5):571-576.

[20] Yeh W-C, Cao Z, Classon M, McKnight SL. Cascade regulation of terminal adipocyte differentiation by three members of the C/EBP family of leucine zipper proteins. Genes and Development. 1995;9(2):168-181.

[21] Rosen ED, Hsu C-H, Wang X, et al. C/EBP $\alpha$ induces adipogenesis through PPAR $\gamma$ : a unified pathway. Genes and Development. 2002;16(1):22-26.

[22] Gori F, Thomas T, Hicok KC, Spelsberg TC, Riggs BL. Differentiation of human marrow stromal precursor cells: bone morphogenetic protein-2 increases OSF2/CBFA1, enhances osteoblast commitment, and inhibits late adipocyte maturation. Journal of Bone and Mineral Research. 1999;14(9):15221535.

[23] Lecka-Czernik B, Gubrij I, Moerman EJ, et al. Inhibition of Osf2/Cbfa1 expression and terminal osteoblast differentiation by PPAR $\gamma 2$. Journal of Cellular Biochemistry. 1999;74(3):357371.

[24] Lecka-Czernik B, Moerman EJ, Grant DF, Lehmann JM, Manolagas SC, Jilka RL. Divergent effects of selective peroxisome proliferator-activated receptor- $\gamma 2$ ligands on adipocyte versus osteoblast differentiation. Endocrinology. 2002;143(6):2376-2384.

[25] Gimble JM, Robinson CE, Wu X, et al. Peroxisome proliferator-activated aeceptor- $\gamma$ activation by thiazolidinediones induces adipogenesis in bone marrow stromal cells. Molecular Pharmacology. 1996;50(5):1087-1094.

[26] Rzonca SO, Suva LJ, Gaddy D, Montague DC, Lecka-Czernik B. Bone is a target for the antidiabetic compound rosiglitazone. Endocrinology. 2004;145(1):401-406.

[27] Lazarenko OP, Rzonca SO, Suva LJ, Lecka-Czernik B. Netoglitazone is a PPAR-gamma ligand with selective effects on bone and fat. Bone. 2006;38(1):74-84.

[28] Ali AA, Weinstein RS, Stewart SA, Parfitt AM, Manolagas SC, Jilka RL. Rosiglitazone causes bone loss in mice by suppressing osteoblast differentiation and bone formation. Endocrinology. 2005;146(3):1226-1235.

[29] Sottile V, Seuwen K, Kneissel M. Enhanced marrow adipogenesis and bone resorption in estrogen-deprived rats treated with the PPARgamma agonist BRL49653 (rosiglitazone). Calcified Tissue International. 2004;75(4):329-337.

[30] Akune T, Ohba S, Kamekura S, et al. PPAR $\gamma$ insufficiency enhances osteogenesis through osteoblast formation from bone marrow progenitors. Journal of Clinical Investigation. 2004;113(6):846-855.

[31] Morey-Holton ER, Globus RK. Hindlimb unloading of growing rats: a model for predicting skeletal changes during space flight. Bone. 1998;22(suppl 5):83S-88S.

[32] Wronski TJ, Morey ER. Skeletal abnormalities in rats induced by simulated weightlessness. Metabolic Bone Disease and Related Research. 1982;4(1):69-75.

[33] Machwate M, Zerath E, Holy X, et al. Skeletal unloading in rat decreases proliferation of rat bone and marrow-derived osteoblastic cells. American Journal of Physiology - Endocrinology and Metabolism. 1993;264(5):E790-E799.

[34] Drissi H, Lomri A, Lasmoles F, Holy X, Zerath E, Marie PJ. Skeletal unloading induces biphasic changes in insulin-like growth factor-I mRNA levels and osteoblast activity. Experimental Cell Research. 1999;251(2):275-284.

[35] Bikle DD, Sakata T, Halloran BP. The impact of skeletal unloading on bone formation. Gravitational and Space Biology Bulletin. 2003;16(2):45-54.
[36] Marie PJ, Zerath E. Role of growth factors in osteoblast alterations induced by skeletal unloading in rats. Growth Factors. 2000;18(1):1-10.

[37] Zhang R, Supowit SC, Klein GL, et al. Rat tail suspension reduces messenger RNA level for growth factors and osteopontin and decreases the osteoblastic differentiation of bone marrow stromal cells. Journal of Bone and Mineral Research. 1995;10(3):415-423.

[38] Bikle DD, Harris J, Halloran BP, Morey-Holton E. Altered skeletal pattern of gene expression in response to spaceflight and hindlimb elevation. The American Journal of Physiology. 1994;267(6 pt 1):E822-E827.

[39] Machwate M, Zerath E, Holy X, Pastoureau P, Marie PJ. Insulin-like growth factor-I increases trabecular bone formation and osteoblastic cell proliferation in unloaded rats. Endocrinology. 1994;134(3):1031-1038.

[40] Shiiba M, Arnaud SB, Tanzawa H, Uzawa K, Yamauchi M. Alterations of collagen matrix in weight-bearing bones during skeletal unloading. Connective Tissue Research. 2001;42(4):303-311.

[41] Wakley GK, Portwood JS, Turner RT. Disuse osteopenia is accompanied by downregulation of gene expression for bone proteins in growing rats. The American Journal of Physiology. 1992;263(6 pt 1):E1029-E1034.

[42] Keila S, Pitaru S, Grosskopf A, Weinreb M. Bone marrow from mechanically unloaded rat bones expresses reduced osteogenic capacity in vitro. Journal of Bone and Mineral Research. 1994;9(3):321-327.

[43] Ahdjoudj S, Lasmoles F, Holy X, Zerath E, Marie PJ. Transforming growth factor $\beta 2$ inhibits adipocyte differentiation induced by skeletal unloading in rat bone marrow stroma. Journal of Bone and Mineral Research. 2002;17(4):668-677.

[44] Ahdjoudj S, Kaabeche K, Holy X, et al. Transforming growth factor- $\beta$ inhibits CCAAT/enhancer-binding protein expression and PPAR $y$ activity in unloaded bone marrow stromal cells. Experimental Cell Research. 2005;303(1):138-147.

[45] Duncan RL, Turner CH. Mechanotransduction and the functional response of bone to mechanical strain. Calcified Tissue International. 1995;57(5):344-358.

[46] El Haj AJ, Minter SL, Rawlinson SCF, Suswillo R, Lanyon LE. Cellular responses to mechanical loading in vitro. Journal of Bone and Mineral Research. 1990;5(9):923-932.

[47] Jones DB, Nolte H, Scholubbers J-G, Turner E, Veltel D. Biochemical signal transduction of mechanical strain in osteoblast-like cells. Biomaterials. 1991;12(2):101-110.

[48] Duncan RL. Transduction of mechanical strain in bone. Gravitational and Space Biology Bulletin. 1995;8(2):49-62.

[49] Shyy JY-J, Chien S. Role of integrins in cellular responses to mechanical stress and adhesion. Current Opinion in Cell Biology. 1997;9(5):707-713.

[50] Moursi AM, Globus RK, Damsky CH. Interactions between integrin receptors and fibronectin are required for calvarial osteoblast differentiation in vitro. Journal of Cell Science. 1997;110(18):2187-2196.

[51] Xiao G, Wang D, Benson MD, Karsenty G, Franceschi RT. Role of the $\alpha 2$-integrin in osteoblast-specific gene expression and activation of the Osf2 transcription factor. Journal of Biological Chemistry. 1998;273(49):32988-32994.

[52] Yuge L, Okubo A, Miyashita T, et al. Physical stress by magnetic force accelerates differentiation of human osteoblasts. Biochemical and Biophysical Research Communications. 2003;311(1):32-38. 
[53] Tanabe Y, Koga M, Saito M, Matsunaga Y, Nakayama K. Inhibition of adipocyte differentiation by mechanical stretching through ERK-mediated downregulation of PPAR $\gamma 2$. Journal of Cell Science. 2004;117(16):3605-3614.

[54] McBeath R, Pirone DM, Nelson CM, Bhadriraju K, Chen CS. Cell shape, cytoskeletal tension, and RhoA regulate stem cell lineage commitment. Developmental Cell. 2004;6(4):483-495.

[55] Gimble JM, Zvonic S, Floyd ZE, Kassem M, Nuttall ME. Playing with bone and fat. Journal of Cellular Biochemistry. 2006;98(2):251-266.

[56] Centrella M, McCarthy TL, Canalis E. Transforming growth factor-beta and remodeling of bone. Journal of Bone and Joint Surgery - Series A. 1991;73(9):1418-1428.

[57] Torti FM, Torti SV, Larrick JW, Ringold GM. Modulation of adipocyte differentiation by tumor necrosis factor and transforming growth factor beta. Journal of Cell Biology. 1989;108(3):1105-1113.

[58] Choy L, Skillington J, Derynck R. Roles of autocrine TGF- $\beta$ receptor and Smad signaling in adipocyte differentiation. Journal of Cell Biology. 2000;149(3):667-682.

[59] Machwate M, Zerath E, Holy X, et al. Systemic administration of transforming growth factor- $\beta 2$ prevents the impaired bone formation and osteopenia induced by unloading in rats. Journal of Clinical Investigation. 1995;96(3):1245-1253.

[60] Hu E, Kim JB, Sarraf P, Spiegelman BM. Inhibition of adipogenesis through MAP kinase-mediated phosphorylation of PPAR $\gamma$. Science. 1996;274(5295):2100-2103.

[61] Adams M, Reginato MJ, Shao D, Lazar MA, Chatterjee VK. Transcriptional activation by peroxisome proliferatoractivated receptor $\gamma$ is inhibited by phosphorylation at a consensus mitogen-activated protein kinase site. Journal of Biological Chemistry. 1997;272(8):5128-5132.

[62] Camp HS, Tafuri SR. Regulation of peroxisome proliferatoractivated receptor $\gamma$ activity by mitogen-activated protein kinase. Journal of Biological Chemistry. 1997;272(16):1081110816.

[63] Jaiswal RK, Jaiswal N, Bruder SP, Mbalaviele G, Marshak DR, Pittenger MF. Adult human mesenchymal stem cell differentiation to the osteogenic or adipogenic lineage is regulated by mitogen-activated protein kinase. Journal of Biological Chemistry. 2000;275(13):9645-9652.

[64] Nuttall ME, Gimble JM. Controlling the balance between osteoblastogenesis and adipogenesis and the consequent therapeutic implications. Current Opinion in Pharmacology. 2004;4(3):290-294.

[65] Ahdjoudj S, Fromigué O, Marie PJ. Plasticity and regulation of human bone marrow stromal osteoprogenitor cells: potential implication in the treatment of age-related bone loss. Histology and Histopathology, Cellular and Molecular Biology. 2004;19(1):151-158. 


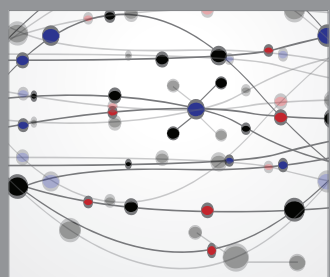

The Scientific World Journal
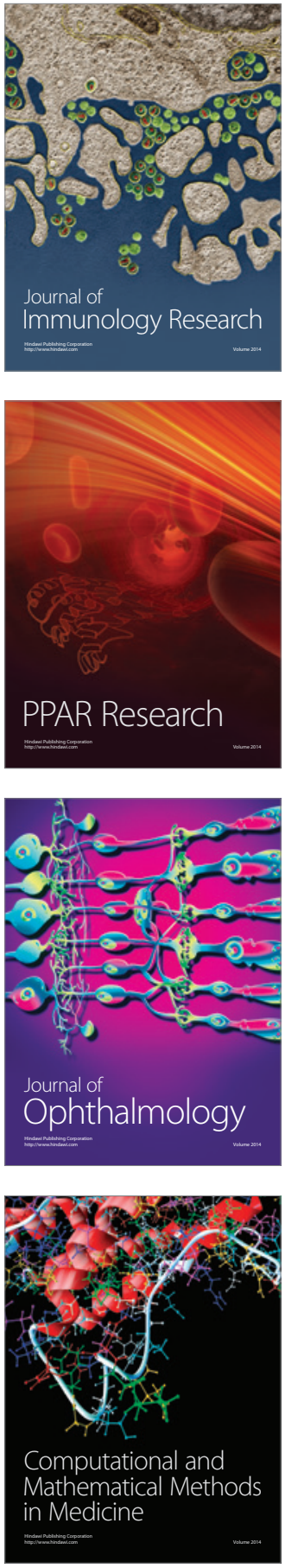

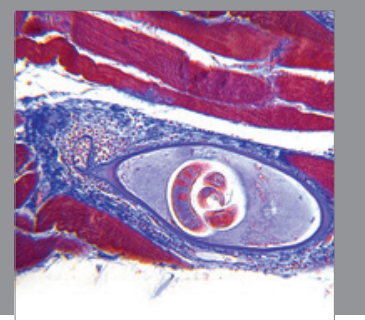

Gastroenterology

Research and Practice
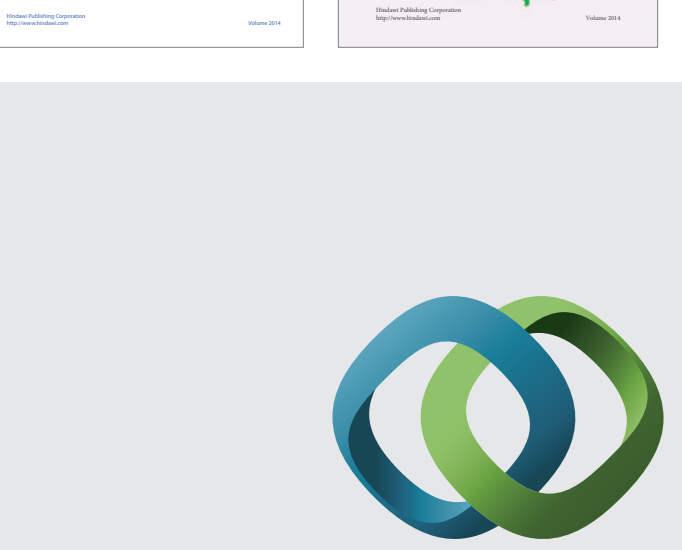

\section{Hindawi}

Submit your manuscripts at

http://www.hindawi.com
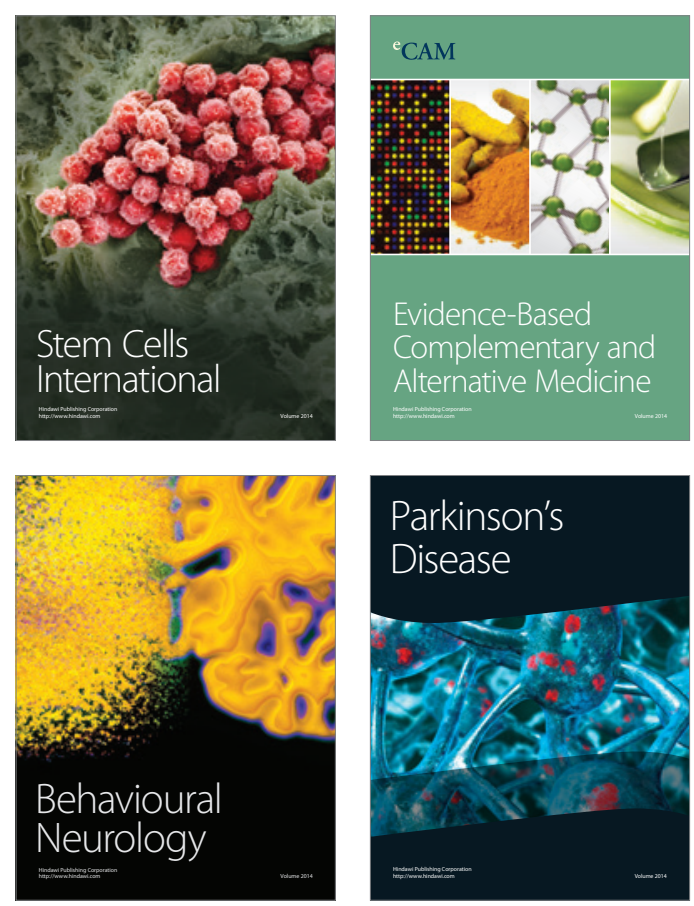

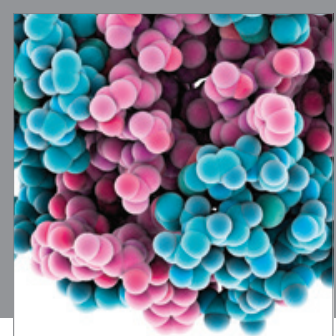

Journal of
Diabetes Research

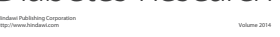

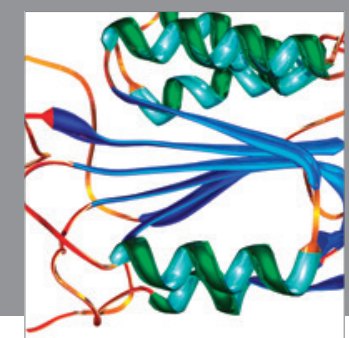

Disease Markers
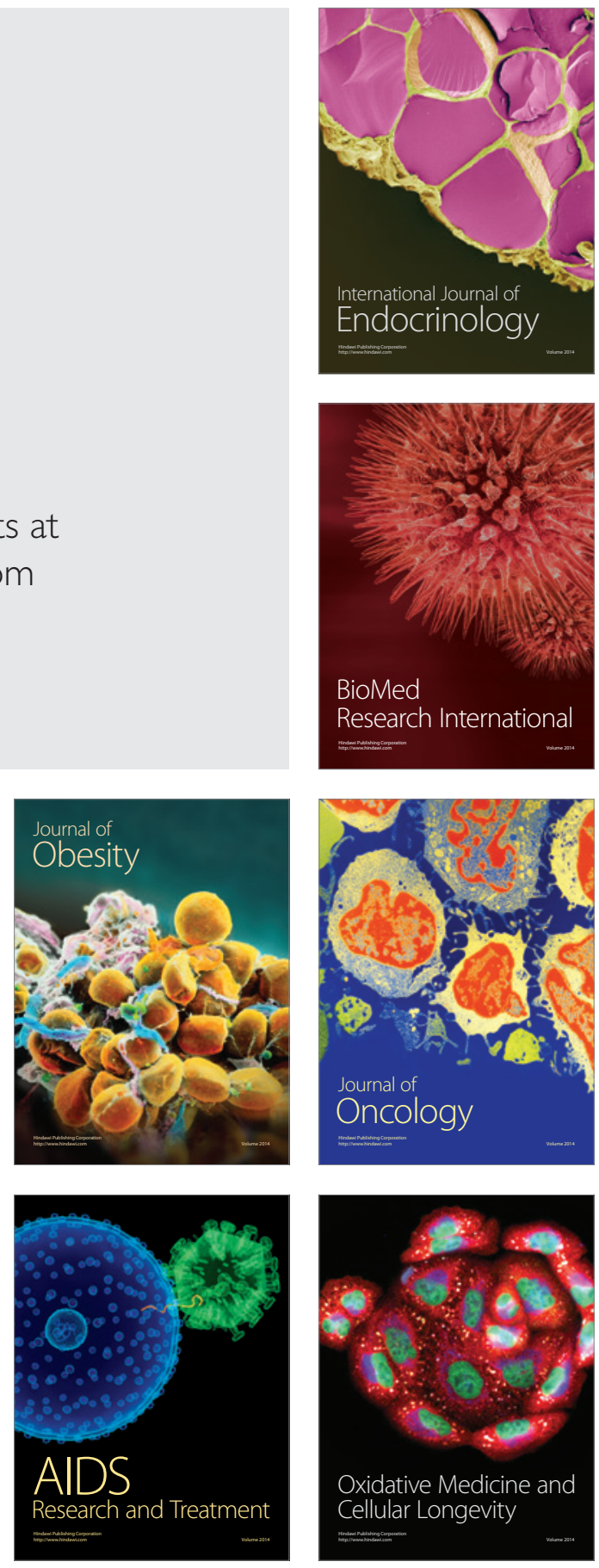